\title{
Optimal Hemodialysis Prescription: Do Children Need More Than a Urea Dialysis Dose?
}

\author{
Fischbach Michel, ${ }^{1}$ Zaloszyc Ariane, ${ }^{1}$ Schaefer Betti, ${ }^{2}$ and Schmitt Claus Peter ${ }^{2}$ \\ ${ }^{1}$ Nephrology Dialysis Transplantation Children's Unit, University Hospital Hautepierre, Avenue Molière, 67098 Strasbourg, France \\ ${ }^{2}$ Division of Pediatric Nephrology, Center for Pediatric and Adolescent Medicine, INF 430, 69120 Heidelberg, Germany
}

Correspondence should be addressed to Fischbach Michel, michel.fischbach@chru-strasbourg.fr

Received 11 February 2011; Accepted 15 March 2011

Academic Editor: Franz Schaefer

Copyright () 2011 Fischbach Michel et al. This is an open access article distributed under the Creative Commons Attribution License, which permits unrestricted use, distribution, and reproduction in any medium, provided the original work is properly cited.

\begin{abstract}
When prescribing hemodialysis in children, the clinician should first establish an adequate regimen, before seeking to optimize the treatment (Fischbach et al. 2005). A complete dialysis dose should consist of a urea dialysis dose and a determined convective volume. Intensified and more frequent dialysis regimens should not be considered exclusively as rescue therapy. Interestingly, a recent single-center study demonstrated that frequent on-line HDF provides an optimal dialysis prescription, both in terms of blood pressure control (and therefore avoidance of left ventricular hypertrophy), and catch-up growth, that is, no malnutrition or cachexia and less resistance to growth hormone. Nevertheless, this one-center experience would benefit from a prospective randomized study.
\end{abstract}

\section{Introduction}

Over the past 20 years, children receiving dialysis have benefited not only from advances in modern technology, but also from improvements in clinical management. Nevertheless, conventional haemodialysis performed three times a week still results in an increased risk of cardiovascular morbidity and impaired growth in children $[1,2]$. The "HEMO" study [3] found that the prescription of a high urea dialysis dose in hemodialysis performed three times a week in adults failed to result in an improvement in clinical outcome. Therefore, "a complete dialysis dose" should be prescribed, that is, not only a urea dialysis dose (a small solute diffusive clearance) [4] but also a convective dialysis volume (middle molecule uremic toxin clearance) [5]. At present, despite great interest and feasibility, hemodiafiltration is rarely performed [6-8]. However, the case for performing intensified and/or more frequent hemodialysis regimens in both children [9-13] and adults has been put forward [14-17]. All intensified treatment modalities, ranging from daily procedures to long intermittent hemodialysis sessions, clearly improve patient outcome in terms of mortality and morbidity. In children, daily on-line hemodiafiltration has even been found to promote catch-up growth $[9,18]$. However, intensive and daily dialysis is rarely performed as a long-term dialysis regimen for "all patients" as it is often only considered as a rescue therapy [15].

\section{Urea Dialysis Dose For Children}

Urea kinetic modeling is generally accepted as a method for evaluating the dialysis dose prescribed [19], despite the fact that it is of limited value in the assessment of dialysis adequacy [4].

Quantification of dialysis is based on a urea dialysis dose, that is, $K t / V$, (dialyzer urea clearance $(K)$ multiplied by duration $(t)$ of the dialysis session and divided by urea volume $(V)$ of distribution. On-line urea clearance measurements, which are currently available on modern dialysis machines, make it easy to calculate the dialysis dose $(K t)$ and, thus, allow the clinician to calculate the $K t / V$ for each session, providing an estimation of $V$ which is assumed to be equal to the total body water. Impedancemetry [20] is of clinical interest when estimating $V$, as it does not require blood sampling to be performed. However, it 
does require the use and availability of a specific machine (BCM, Fresenius Medical Care). The use of anthropometric formulas to calculate " $V$ " has been found to be less accurate especially in children [19]. An indirect method of calculating " $V$ " can be achieved using the ratio $K t / K t / V$ [20], where $K t$ is obtained from the ionic dialysance provided by the dialysis monitor, and $K t / V$ is obtained from the second generation of Daugirdas formula [19], which requires blood samples to be taken before and after the dialysis session. The on-line urea $K t / V$ assessment performed by the dialysis monitor gives out a single pool $K t / V(\operatorname{spK} t / V)$ [19], with a proposed target dose of 1.4 per dialysis session in anuric patients $[19,21]$. Nevertheless, spKt/V does not take into account postdialytic urea rebound. Therefore, formulas for estimating the equilibrated $K t / V(\mathrm{e} K t / V)$ are available [4, $19,21]$. Due to the need for postdialytic blood sampling, in practice $s p K t / V$ is a clinically acceptable way of monitoring HD adequacy, at least in a thrice-weekly hemodialysis regimen. In cases where hemodialysis is performed more frequently, standard $K t / V($ st $K t / V)$ should be calculated [22]. This formula integrates $\mathrm{spK} t / \mathrm{V}$ and $\mathrm{eKt} / \mathrm{V}$ in order to account for urea peaks and valleys. A dialysis dose based on body surface area $(\mathrm{SAN}-\mathrm{st} K t / V)$ has been suggested to be a more accurate way of determining the urea dialysis dose required in children: a dose over 2.45 [23] should be considered to be an optimal dialysis dose, promoting catch up statural growth in children on chronic dialysis. Nevertheless, a complete dialysis dose [5] should be preferred to an urea dialysis dose, "only" a diffusive dialysis dose [5]. The "complete dialysis dose" is difficult to define and stays under discussion $[4,5]$ : beside the urea dialysis dose, a diffusive dialysis dose, a convective dialysis dose could be proposed $[6,15,24]$, based on phosphate dialytic removal and on the achieved beta 2 microglobulinemia.

\section{Convective Dialysis Dose: The Convective Volume per Dialysis Session}

Uremic toxins can be categorized into three groups: free water soluble low-molecular-weight solutes such as urea, middle-sized solutes such as beta 2 microglobulin $(\beta 2 \mathrm{~m})$, and protein-bound solutes such as p-cresol acid [24]. The phosphate ion is small, but not "free" as it is surrounded by water molecules; therefore, it has a clearance profile similar to that of the middle-sized molecules. The removal of uremic toxins by dialysis relies upon a combination of the diffusion process, convective mass transport, and membrane adsorption [25]. Haemodialysis (HD) provides optimal removal of low-molecular-weight uremic toxins such as urea due to the diffusive flow of solutes. Conversely, the convective flow of solutes which mainly occurs in hemofiltration (HF) and hemodiafiltration (HDF) results in the removal of middlesized and large molecules. Convection and diffusion are presented as two separate phenomena, but in practice they are on a continuous interference. Nevertheless, the concept of a complete dialysis dose [5], which includes not only a urea dialysis dose, that is, $K t / V$ urea, but also a convective dialysis dose, that is, the convective volume achieved per dialysis session, may be of importance in terms of patient outcomein particular resulting in an improvement in cardiovascular mortality $[6,26]$.

Hemodiafiltration is a combination of HD and HF performed during the same procedure, allowing a determined convective flow per dialysis session. The weight loss that arises when HD occurs only ensures a convective flow equal to the ultrafiltration rate, that is, a small convective volume. During conventional HD with high-flux filters, "internal" HDF occurs due to back filtration of the dialysate, providing only a slightly larger but nondetermined convective volume. Moreover, the dialysate used is not always a sterile, nonpyrogenic substitution fluid, and therefore may provoke systemic inflammation $[28,29]$. Altogether, on-line hemodiafiltration, that is, substitution fluid prepared from ultrafiltration of the ultrapure dialysate, which is a safe routine replacement therapy $[6,7,17,30,31]$, enables the use of a determined high convective volume throughout the dialysis session, impacting on both solute removal and clinical outcome. HDF offers improved control of phosphate when compared to both HD and high-flux HD [6, 7]. Predialysis $\beta 2 \mathrm{~m}$ serum levels are decreased during OL-HDF; the $\beta 2 \mathrm{~m}$ dialytic removal correlates with the convective volume achieved. High-efficiency $\mathrm{HDF}$, as defined in adult patients in postdilution mode using a convective dose of more than $15 \mathrm{~L}$ per session, is superior to low-efficiency HDF both in terms of solute removal and patient outcome $[6,7]$. As demonstrated by a recent single centre study [18], when performed on a daily basis, on-line HDF using a convective volume in pre dilution mode of 18 to $27 \mathrm{~L} / \mathrm{m}^{2}$ per procedure even promotes catch up growth in children. At present, it is not known if the different intensive hemodialysis regimens available are equivalent in terms of their growth promoting capacity $[11,21]$.

\section{Hemodialysis Fluids Purity}

The purity, in terms of microbial contaminants measured as colony forming units (CFU) and endotoxins units (EU), is recorded for the different fluids used in the dialysis procedure [7]. The purity should be carefully assessed in order to limit the risk of patient's systemic inflammation, in the clinical setting illustrated by the surrogate parameter of an elevated CRP. Standard quality dialysis fluid (bacterial count $<100 \mathrm{CFU} / \mathrm{ml}$; endotoxin units $<0.50 \mathrm{EU} / \mathrm{ml}$ ) is not appropriate for use with high-flux filters for HD, due to the internal convective flow, that is, the backfiltration. Highflux membranes require the use of ultrapure dialysate, that is, bacterial count $<0.1 \mathrm{CFU} / \mathrm{mL}$; endotoxin count $<0.05 \mathrm{UI} / \mathrm{mL}$. For "at risk" patients, the current European guidelines recommend the use of highly permeable membranes in HD [27]. This results in restricted "internal" HDF, as only a small nondetermined convective volume is used.

\section{Blood Pressure Control, Cardiovascular Disease}

Repeated conventional dialysis sessions have an additive effect which contributes, towards the cardiovascular risk 
TABLE 1: Adequate hemodialysis prescription for children: more than a urea dialysis dose (adapted from $[4,5,11,19,27]$ ).

(i)

Hemodialysis should be performed in a pediatric dialysis center, in order to ensure optimal care and child development (nutrition, growth, education)

(ii) A complete dialysis dose should be prescribed, not only a urea dialysis dose, that is, sp $K t / V>1.4$ in anuric patients, but also a high convective volume. Phosphate and $\beta 2 \mathrm{~m}$ can be used as markers for the removal of "middle-sized uremic molecules."

Prefer biocompatible materials where possible, that is, high-flux membranes which provide enhanced molecular permeability.

(iii) High-flux membranes, especially in cases of high hydraulic permeability, require the use of ultrapure dialysate, that is, a bacterial count $<0.1 \mathrm{CFU} / \mathrm{mL}$ and an endotoxin count $<0.05 \mathrm{UI} / \mathrm{mL}$.

(iv) Control blood pressure and aim for prevention of cardiovascular sequelae such as left ventricular hypertrophy, left ventricular dysfunction, coronary artery calcifications, and vascular stiffness.

(v) Ensure optimal nutrition, that is, limit malnutrition and cachexia in order to avoid muscle wasting and to promote growth and development.

(vi) Propose an intensified hemodialysis regimen, that is, longer and/or more frequent dialysis in center or at home, not only for use as a rescue therapy.

Deliver the highest standard of dialysis possible in all cases, that is, biocompatibility of the material used, monitor the purity of the

(vii) dialysate, and use a controlled determined convective flow instead of an internal, small, nondetermined flow with backfiltration into the dialyzer.

profile in children, that is, morbidity and mortality. Adverse effects related to dialysis include: high blood pressure, left ventricular hypertrophy or impaired left ventricular function, elevated calcium/phosphate resulting in calcification of blood vessels (particularly vascular/coronnary calcifications), and systemic inflammation. The above list accounts for the vast majority of dialysis related risks to the cardiovascular system, contributing towards increased morbidity and mortality $[2,32]$.

In children on chronic conventional hemodialysis, hypertension is common. For example, $79 \%$ of children on HD in the United States have an elevated BP at the start of the dialysis session [33]. A further study found that Left ventricular hypertrophy (LVH) was worryingly common ( $82 \%$ of patients) in children at the initiation of dialysis, and remained frequent $(82 \%)$ and severe $(59 \%)$ after 2 years of maintenance conventional hemodialysis [34].

In children on conventional $\mathrm{HD}, \mathrm{LVH}$ may be improved [35] by optimizing the sodium balance, for example, by strict dietary control of sodium intake, dry weight achievement, and supplementary dialysis time. Overall however, intensified hemodialysis regimens should not be disregarded in the hope of improving cardiovascular health [11], and they should, therefore, not be considered exclusively as rescue therapy [15].

\section{Protein Wasting: Cachexia}

Malnutrition is common amongst children on chronic haemodialysis. However, they are not only malnourishedwhich infers that dietary supplementation would be curative, but they are also cachexic (i.e., in a state of protein loss). Malnutrition and cachexia combined are two important factors which contribute towards the protein wasting seen in uremic patients [36]. Conventional hemodialysis performed three times a week requires patients to stick to a restrictive diet which limits the intake of protein, water, sodium, potassium, and phosphate, whilst at the same time maintaining an adequate calorie intake. Due to limited uremic toxin removal, chelators of phosphate and potassium are often prescribedbut these are also factors which contribute towards anorexia, that is, malnutrition. Conversely, if the dialysed child has a good appetite, he is at risk of increased weight gain between dialysis sessions and of raised blood phosphate or potassium levels and of major metabolic acidosis. In such circumstances, the duration of the dialysis procedure is often increased from 4 to 5 hours, and sometimes an additional dialysis session later in the week may be required. The child on long-term dialysis often considers these changes or adaptions to be a form of punishment, and he responds in turn by fasting and becoming increasingly less compliant and more opposed to the procedure. Aside from malnutrition, protein catabolism is an independent factor which plays a major role in the muscle wasting and poor linear growth that result despite rh GH therapy. Loss of protein stores, that is, more cachexia than malnutrition [37] is a multifactorial event, caused by: inflammation [38], acidosis, uremic toxin retention, and volume overload, that is, poor blood pressure control. Malnutrition and cachexia should be limited by more intensive and frequent hemodialysis. Interesting, online HDF performed on a daily basis has been found to reverse both cachexia and malnutrition and to promote catch up growth in children [18].

\section{Conclusions}

In children, an adequate hemodialysis prescription requires more than simply a urea dialysis dose (Table 1). If economically feasible, high-flux membranes should be used in combination with ultrapure disposable dialysate. Online hemodiafiltration, that is, substitution fluid prepared from ultrafiltration of the ultrapure dialysate, is a safe routine replacement therapy which has a positive impact not only on the removal of solutes such as phosphate or $\beta 2 \mathrm{~m}$, but also on clinical outcome. Intensified and more frequent hemodialysis regimens, that is, high-flux HD or 
on-line HDF, provide adequate hemodialysis in children, and should, therefore, not exclusively be used as rescue therapy. Nevertheless, in young children with renal residual clearance, peritoneal dialysis remains an excellent choice of chronic at home dialysis modality.

\section{References}

[1] E. Bérard, J. L. André, G. Guest et al., "Long-term results of rhGH treatment in children with renal failure: experience of the French Society of Pediatric Nephrology," Pediatric Nephrology, vol. 23, no. 11, pp. 2031-2038, 2008.

[2] J. W. Groothoff, M. P. Gruppen, M. Offringa et al., "Mortality and causes of death of end-stage renal disease in children: a dutch cohort study," Kidney International, vol. 61, no. 2, pp. 621-629, 2002.

[3] G. Eknoyan, G. J. Beck, A. K. Cheung et al., "Effect of dialysis dose and membrane flux in maintenance hemodialysis," New England Journal of Medicine, vol. 347, no. 25, pp. 2010-2019, 2002.

[4] S. L. Goldstein, "Adequacy of dialysis in children: does small solute clearance really matter?" Pediatric Nephrology, vol. 19, no. 1, pp. 1-5, 2004.

[5] M. Fischbach, H. Fothergill, A. Zaloszyc, and L. Seuge, "Hemodiafiltration: the addition of convective flow to hemodialysis," Pediatric Nephrology. In press.

[6] P. J. Blankestijn, I. Ledebo, and B. Canaud, "Hemodiafiltration: clinical evidence and remaining questions," Kidney International, vol. 77, no. 7, pp. 581-587, 2010.

[7] I. Ledebo and P. J. Blankestijn, "Haemodiafiltration-optimal efficiency and safety," NDT Plus, vol. 3, no. 1, pp. 8-16, 2010.

[8] M. V. Rocco, "Short daily and nocturnal hemodialysis: new therapies for a new century?" Saudi Journal of Kidney Diseases and Transplantation, vol. 20, no. 1, pp. 1-11, 2009.

[9] M. Fischbach, J. Terzic, V. Laugel et al., "Daily on-line haemodiafiltration: a pilot trial in children," Nephrology Dialysis Transplantation, vol. 19, no. 9, pp. 2360-2367, 2004.

[10] D. F. Georg, E. Peva, J. Tyrell et al., "Home nocturnal hemodialysis in children," Journal of Pediatrics, vol. 143, pp. 383-387, 2005.

[11] D. Müller, M. Zimmering, C. T. Chan, P. A. McFarlane, A. Pierratos, and U. Querfeld, "Intensified hemodialysis regimens: neglected treatment options for children and adolescents," Pediatric Nephrology, vol. 23, no. 10, pp. 1729-1736, 2008.

[12] A. Tom, L. McCauley, L. Bell et al., "Growth during maintenance hemodialysis: impact of enhanced nutrition and clearance," Journal of Pediatrics, vol. 134, no. 4, pp. 464-471, 1999.

[13] A. K. Sharma, "Reassessing hemodialysis adequacy in children: the case for more," Pediatric Nephrology, vol. 16, no. 4, pp. 383-390, 2001.

[14] C. Chazot and G. Jean, "The advantages and challenges of increasing the duration and frequency of maintenance dialysis sessions," Nature Clinical Practice Nephrology, vol. 5, no. 1, pp. 34-44, 2009.

[15] K. Jindal, C. T. Chan, C. Deziel et al., "Hemodialysis clinical practice guidelines for the Canadian Society of Nephrology," Journal of the American Society of Nephrology, vol. 17, no. 3, supplement, pp. S1-27, 2006.

[16] A. Pierratos, "New approaches to hemodialysis," Annual Review of Medicine, vol. 347, pp. 2010-2019, 2004.
[17] C. Ronco and D. Cruz, "Hemodiafiltration history, technology, and clinical results," Advances in Chronic Kidney Disease, vol. 14, no. 3, pp. 231-243, 2007.

[18] M. Fischbach, J. Terzic, S. Menouer, C. Dheu, L. Seuge, and A. Zalosczic, "Daily on line haemodiafiltration promotes catchup growth in children on chronic dialysis," Nephrology Dialysis Transplantation, vol. 25, no. 3, pp. 867-873, 2010.

[19] M. Fischbach, A. Edefonti, C. Schröder et al., "Hemodialysis in children: general practical guidelines," Pediatric Nephrology, vol. 20, no. 8, pp. 1054-1066, 2005.

[20] A. Koubaa, J. Potier, H. de Préneuf, G. Queffelou, F. Garcia, and T. Petitclerc, "Estimation of urea distribution volume in hemodialysis patients," Nephrologie et Therapeutique, vol. 6, pp. 532-536, 2010.

[21] J. D. Mahan and H. P. Patel, "Recent advances in pediatric dialysis: a review of selected articles," Pediatric Nephrology, vol. 23, no. 10, pp. 1737-1747, 2008.

[22] J. K. Leypoldt, "Urea standard $\mathrm{Kt} / \mathrm{V}_{\text {urea }}$ for assessing dialysis treatment adequacy," Hemodialysis International, vol. 8, no. 2, pp. 193-197, 2004.

[23] J. T. Daugirdas, M. G. Hanna, R. Becker-Cohen, and C. B. Langman, "Dose of dialysis based on body surface area is markedly less in younger children than in older adolescents," Clinical Journal of the American Society of Nephrology, vol. 5, no. 5, pp. 821-827, 2010.

[24] R. Vanholder, U. Baurmeister, P. Brunet, G. Cohen, G. Glorieux, and J. Jankowski, "A bench to bedside view of uremic toxins," Journal of the American Society of Nephrology, vol. 19, no. 5, pp. 863-870, 2008.

[25] A. Santoro and G. Guadagni, "Dialysis membrane: from convection to adsorption," NDT Plus, vol. 3, no. 1, supplement, pp. i36-i39, 2010.

[26] B. Canaud, J. L. Bragg-Gresham, M. R. Marshall et al., "Mortality risk for patients receiving hemodiafiltration versus hemodialysis: European results from the DOPPS," Kidney International, vol. 69, no. 11, pp. 2087-2093, 2006.

[27] J. Tattersall, B. Canaud, O. Heimburger, L. Pedrini, D. Schneditz, and W. Van Biesen, "High-flux or low-flux dialysis: a position statement following publication of the Membrane Permeability Outcome study," Nephrology Dialysis Transplantation, vol. 25, no. 4, pp. 1230-1232, 2010.

[28] V. Panichi, G. M. Rizza, S. Paoletti et al., "Chronic inflammation and mortality in haemodialysis: effect of different renal replacement therapies. Results from the RISCAVID study," Nephrology Dialysis Transplantation, vol. 23, no. 7, pp. 23372343, 2008.

[29] E. Vilar, A. C. Fry, D. Weelsted, J. E. Tattersall, R. N. Greewood, and K. Farrington, "Long term outcomes in on-line hemodialfiltration and high flux hemodialysis: a comparative study," Clinical Journal of the American Society of Nephrology, vol. 4, no. 12, pp. 1944-1953, 2009.

[30] B. Canaud, J. Y. Bosc, H. Leray et al., "On-line haemodiafiltration: state of the art," Nephrology Dialysis Transplantation, vol. 13, no. 5, pp. 5-11, 1998.

[31] F. Maduell, C. Del Pozo, H. Garcia et al., "Change from conventional haemodiafiltration to on-line haemodiafiltration," Nephrology Dialysis Transplantation, vol. 14, no. 5, pp. 12021207, 1999.

[32] R. N. Foley, P. S. Parfrey, and M. J. Sarnak, "Epidemiology of cardiovascular disease in chronic renal disease," Journal of the American Society of Nephrology, vol. 9, no. 12, pp. S16-S23, 1998. 
[33] B. M. Chavers, C. A. Solid, F. X. Daniels et al., "Hypertension in pediatric long-term hemodialysis patients in the United States," Clinical Journal of the American Society of Nephrology, vol. 4, no. 8, pp. 1363-1369, 2009.

[34] M. M. Mitsnefes, G. M. Barletta, I. G. Dresner et al., "Severe cardiac hypertrophy and long-term dialysis: the Midwest Pediatric Nephrolgy Consortium study," Pediatric Nephrology, vol. 21, no. 8, pp. 1167-1170, 2006.

[35] T. Ulinski, J. Genty, C. Viau, I. Tillous-Borde, and G. Deschênes, "Reduction of left ventricular hypertrophy in children undergoing hemodialysis," Pediatric Nephrology, vol. 21, no. 8, pp. 1171-1178, 2006.

[36] M. Fischbach, C. Dheu, L. Seuge, and N. Orfanos, "Hemodialysis and nutritional status in children: malnutrition and Cachexia," Journal of Renal Nutrition, vol. 19, no. 1, pp. 9194, 2009.

[37] V. R. Rajan and W. E. Mitch, "Muscle wasting in chronic kidney disease: the role of the ubiquitin proteasome system and its clinical impact," Pediatric Nephrology, vol. 23, no. 4, pp. 527-535, 2008.

[38] W. W. Cheung, K. H. Paik, and R. H. Mak, "Inflammation and cachexia in chronic kidney disease," Pediatric Nephrology, vol. 25, no. 4, pp. 711-724, 2010. 


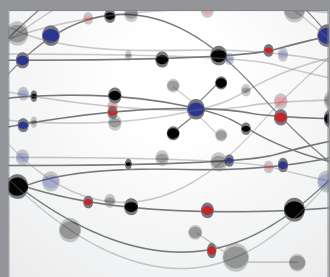

The Scientific World Journal
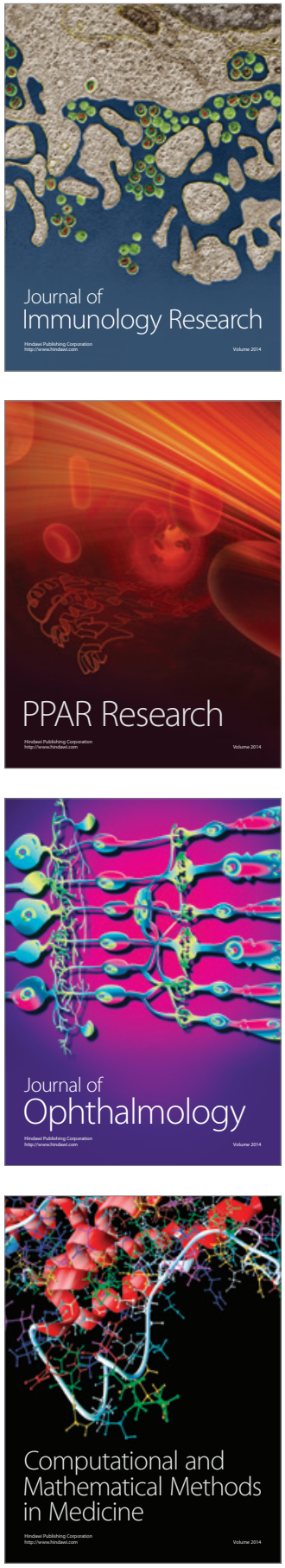

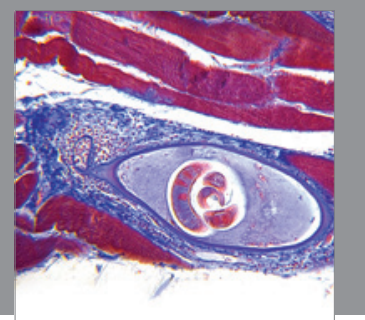

Gastroenterology

Research and Practice
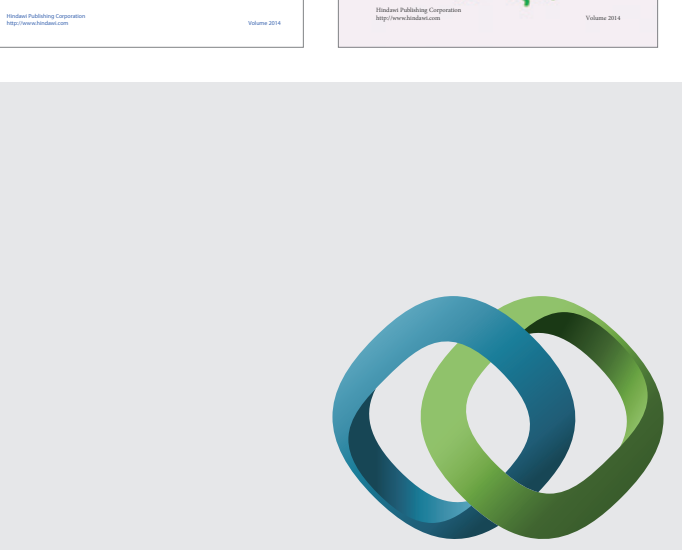

\section{Hindawi}

Submit your manuscripts at

http://www.hindawi.com
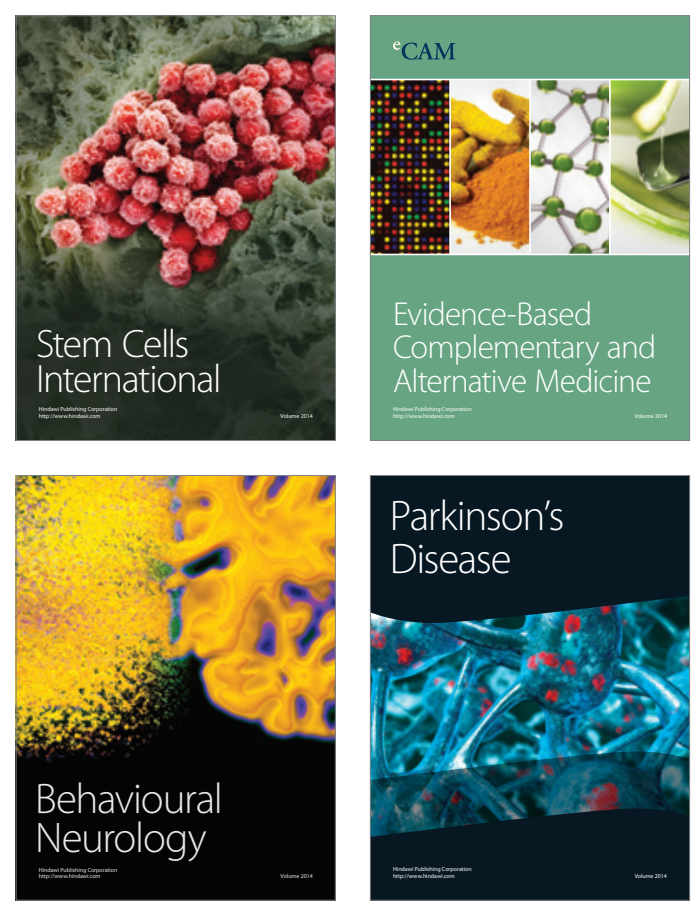

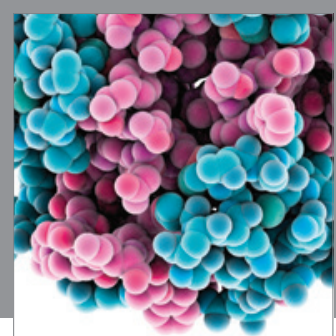

Journal of
Diabetes Research

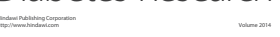

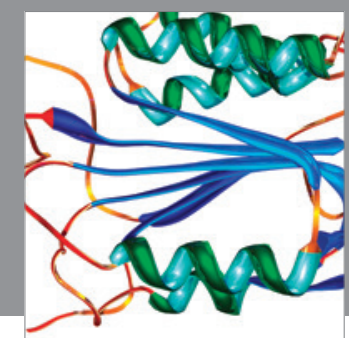

Disease Markers
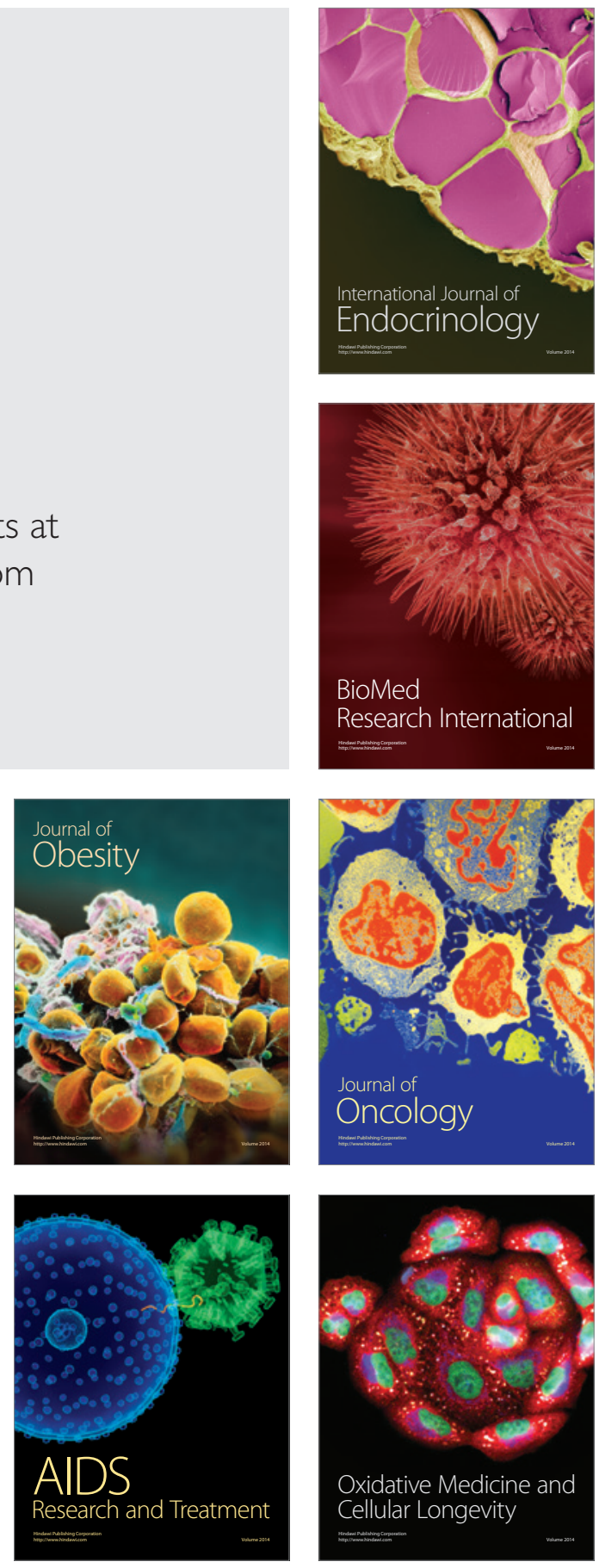